А.И. КРЮКОВ, Д.М.Н., ПрОфесСор, Н.Л. КУНЕЛЬСКАЯ, Д.М.Н., ПрОфесСОр, Г.Ю. ЦАРАПКИН, К.М.Н., Г.Н. ИЗОТОВА, К.б.Н., А.С. ТОВМАСЯН, К.М.Н., Ю.В. ЛУЧШЕВА, К.М.Н.

Московский научно-практический центр оториноларингологии им. Л.И. Свержевского Департамента здравоохранения г. Москвы

\title{
СОВРЕМЕННАЯ ФИТОТЕРАПИЯ
}

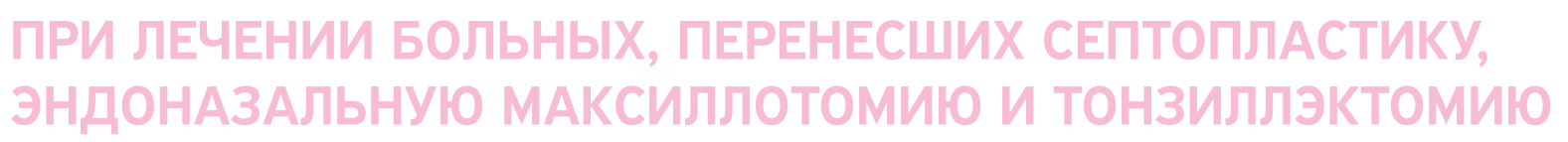

\begin{abstract}
На базе ГБУЗ «НИКИО им. Л.И. Свержевского» обследовано 30 пациентов в возрасте от 21 до 53 лет с искривлением перегородки носа (ИПН), вазомоторным ринитом ( $=10)$, кистой верхнечелюстной пазухи (n = 10) и хроническим тонзиллитом (ТАФ I, II, $\mathbf{n}=10$ ). Все больные поступали для плановых хирургических вмешательств - септопластики с вазотомией нижних носовых раковин, эндоназальной максиллотомии и тонзиллэктомии под КЭТН. Проведенные клинические исследования свидетельствуют о безопасности, эффективности и удобстве применения препарата Умкалор у данной категории пациентов. Умкалор эффективно устраняет субъективные симптомы затруднения носового дыхания, боль при глотании, ускоряет нормализацию показателей носового дыхания, МЦТ, а также показатели интратимпанального давления и может быть рекомендован для лечения в послеоперационном периоде у больных, перенесших хирургическое лечение по поводу септопластики и двусторонней тонзиллэктомии.
\end{abstract}

Ключевые слова: фитопрепараты, секретолитик, антибактериальный эффект.

A.I. KRYUKOV, MD, Prof., N.L. KUNELSKAYA, MD, Prof., G.Y. TSARAPKIN, PhD in medicine, G.N. IZOTOVA, PhD in biology, A.S. TOVMASYAN, PhD in medicine, Y.V. LUCHSHEVA, PhD in medicine

Sverzhevsky Moscow Scientific and Practical Center of Otorhinolaryngology of the Moscow Healthcare Department MODERN PHYTOTHERAPY IN TREATMENT OF PATIENTS WITH PREVIOUS SEPTOPLASTICS, ENDONASAL MAXILLECTOMY AND TONSILLECTOMY

On the premises of the SBUE Sverzhevsky Moscow Scientific and Practical Center of Otorhinolaryngology we examined 30 patients at the age from 21 to 53 years with a deviated nasal septum (IIT), vasomotor rhinitis $(n=10)$, a cyst of the maxillary sinus $(n=10)$ and chronic tonsillitis (TAF. I, II, $n=10$ ). All patients were admitted for planned surgical procedures - septoplasty with vasotomy of inferior turbinates, the endonasal maxillectomy and tonsillectomy under combined endotracheal narcosis. Clinical studies demonstrate safety, efficacy and ease of use of the drug Umckalor in this category of patients. Umckalor effectively eliminates subjective symptoms of nasal breathing obstruction, pain when swallowing, accelerates normalization of nasal breathing, mucosilia transport and indicators of intratympanic pressure and can be recommended for treatment in the postoperative period in patients undergoing surgical treatment for septoplasty and bilateral tonsillectomy.

Keywords: herbal remedies, secretolytic, antibacterial effect.

\section{АКТУАЛЬНОСТЬ}

Инфекционные осложнения являются одной из основных причин неудач в хирургии, в т. ч. и при вмешательствах на ЛОР-органах. Во время таких операций хирург практически никогда не имеет возможности работать в условиях стерильного операционного поля. Поэтому предотвращение послеоперационных инфекционных осложнений и периоперационная профилактика в оториноларингологии всегда были проблемами исключительной значимости. Периоперационная профилактика защищает больного от целого ряда инфекционных осложнений, таких как абсцессы, септицемия, инфицирование инородных тел (например, шовного материала и хирургических имплантатов), а также инфекции сосудов, мочевыводящих, дыхательных путей.

В широком смысле периоперационная профилактика включает в себя такие мероприятия, как строгое соблюдение общепринятых правил асептики и антисептики, использование адекватных методов очистки, мытья и стерилизации инструментария и расходных материалов. На частоту развития хирургической инфекции влияют сбривание волос в области разреза и обработка кожи [1, 2].
Для профилактики послеоперационных инфекций необходимо обеспечить минимальную степень хирургической травмы (щадящее обращение с тканями, использование атравматичного шовного материала), предотвратить инфицирование раны (дезинфекция, промывание), избегать натяжения краев раны швами, ишемии и дегидратации тканей. Большое значение имеет квалификация хирурга. Частота возникновения инфекционных осложнений у неопытного хирурга может быть в 4 раза выше, чем у опытного. Вероятность развития послеоперационной инфекции зависит также от длительности хирургического вмешательства, его этапности и выбранного хирургического доступа [1].

В узком смысле под периоперационной профилактикой инфекций понимают введение с целью предотвращения инфекционных осложнений перед и/или во время операции антимикробных препаратов больным, не имеющим признаков уже развившейся инфекции.

Необходимость периоперационной антибиотикопрофилактики диктуется следующими факторами:

- послеоперационные инфекционные осложнения являются основной причиной заболеваемости и смертности хирургических больных; 
послеоперационные инфекции удлиняют сроки госпитализации, увеличивают стоимость лечения больных и нагрузку на персонал стационара.

Проведение периоперационной антибиотикопрофилактики, как правило, более надежно и экономически эффективно, чем лечение инфекций, развивающихся у больных, которым профилактика не проводилась или проводилась неадекватно. Термин «профилактика» может быть применен только к тем хирургическим вмешательствам, которые выполняются в отсутствие уже развившейся инфекции [3].

В соответствии со стандартной классификацией хирургические вмешательства делят на 4 группы в зависимости от степени микробной обсемененности операционного поля: «чистые», условно «чистые», контаминированные, «грязные».

Согласно этой классификации, применительно к оториноларингологии «чистыми» считаются вмешательства, проводимые при отсутствии травмы или инфекции без проникновения в дыхательные пути, полость рта, глотки, гортани и трахеи. Основными источниками обсеменения раны при таких хирургических вмешательствах являются воздух и другие экзогенные факторы. Примерами таких операций в оториноларингологии являются стапедопластика, эстетическая/косметическая хирургия лица и др. При «чистых» хирургических вмешательствах инфекции возникают менее чем в $5 \%$.

К условно «чистым» относят те вмешательства, которые сопровождаются проникновением в дыхательные пути или пищеварительный тракт при отсутствии в них воспалительного процесса, т. е. без значительного загрязнения операционного поля инфицированным содержимым. Примерами таких операций могут служить внутриносовые вмешательства на перегородке носа, раковинах, при новообразованиях и кистах в околоносовых пазухах (ОНИ), в полостях среднего уха при отсутствии в них активного воспалительного процесса. Частота инфекций при условно «чистых» вмешательствах составляет менее 10\% [4].

К вмешательствам контаминированного типа относят выполняемые при наличии воспалительного процесса (но вне его обострения), т.е. в условиях серьезного нарушения стерильности (плановые хирургические вмешательства при воспалительных заболеваниях уха, глотки, ОНП: санирующие и слухоулучшающие операции на среднем ухе, операции на ОНП при хронических синуситах, тонзиллэктомия и др.). Этот тип вмешательств сопровождается послеоперационными инфекциями примерно в 20\% случаев.

Хирургические вмешательства «грязного» типа включают операции по поводу гнойных инфекционных заболеваний. Вмешательства «грязного» типа сопровождаются инфекционными осложнениями не менее чем в $30 \%$ случаев [3, 5].

При «чистых» хирургических операциях проведение антибиотикопрофилактики обычно не требуется, при условно «чистых» - желательно, а при контаминированных операциях (хирургия верхних дыхательных путей, глотки, уха) - обязательно. При «грязных» операциях показана антибиотикотерапия. Таким образом, периоперационная антибиотикопрофилактика считается важной частью любой операции, при которой частота послеоперационных инфекций превышает 5\% (все контаминированные и ряд условно «чистых» вмешательств).

Антимикробные препараты, выбранные для профилактики септических осложнений при конкретных операциях, должны быть активны в отношении тех микроорганизмов, которые с наибольшей вероятностью являются возбудителями потенциальных осложнений. Цель введения антибиотика - снизить количество микроорганизмов в оперируемом органе ниже критического уровня, необходимого для развития инфекции. В этом отношении бактерицидные антибиотики, безусловно, предпочтительнее бактериостатических.

В связи с растущей резистентностью к применяемым на сегодняшний день известным антибактериальным препаратам становится актуальным поиск новых антибактериальных препаратов, не применяемых для этих целей ранее.

В последние годы в медицине все чаще стали использовать препараты на растительной основе - фитопрепараты.

Достоинством современной фитотерапии является низкий риск развития побочных эффектов. Большинство из этих препаратов хорошо переносятся больными, с меньшими нежелательными последствиями, чем фармацевтические препараты химического происхождения [4]. Конечно же, одним из важных факторов выбора является доступная цена препаратов растительного происхождения. Фитотерапия должна хорошо сочетаться с любой фармакотерапией, повышая ее эффективность и уменьшая риск возникновения побочных эффектов.

Проделанная нами работа посвящена одному из современных фитотерапевтических препаратов, который удовлетворяет всем этим требованиям. Таким является известный в России препарат Умкалор, предназначенный для лечения заболеваний верхних дыхательных путей.

Умкалор - уникальное лекарственное средство растительного происхождения фирмы Dr. Willmar Schwabe (Германия), в состав которого входит оригинальный экстракт из корней южноафриканского растения Pelargonium sidoides - EPs ${ }^{\circledR}$ 7630. Умкалор активирует противовирусные защитные механизмы организма, положительно влияя на неспецифическую иммунную реакцию путем стимуляции фагоцитоза и регуляции активности специфических субстанций хемотаксиса, является индуктором продукции цитокинов (интерферона). Препарат обладает антибактериальным действием, предупреждает присоединение вторичной инфекции. Увеличивает частоту движения ресничек, оказывая секретомоторный эффект. Многочисленные клинические исследования Умкалор, проведенные в разных странах мира, продемонстрировали высокую эффективность и безопасность препарата при лечении заболеваний ЛОР-органов, инфекций верхних дыхательных путей и бронхита как у взрослых, так и у детей старше 1 года [5-7]. Большинство исследований показали превосходный профиль безопасности препарата, 
что позволяет использовать Умкалор в течение длительного времени, а также для профилактики обострений хронических инфекций респираторного тракта [8, 9].

Противопоказаниями к применению являются гиперчувствительность к компонентам препарата, усиленная склонность к кровотечениям, тяжелые заболевания печени и почек, период беременности и лактации. Таким образом, комбинированное антивирусное, антибактериальное, иммуномодулирующее, противовоспалительное, муколитическое и секретомоторное действие Умкалор делают его привлекательным для терапии заболеваний органов дыхания у детей с атопией, поскольку проблема снижения медикаментозной нагрузки у данной группы пациентов является весьма актуальной.

В связи с этим целью исследования явилось изучение клинической эффективности препарата Умкалор в качестве антибиотикопрофилактики в раннем послеоперационном периоде в составе комплексной терапии у пациентов после проведения септопластики, эндоназальной максиллотомии и тонзиллэктомии.

\section{ЗАДАЧИ ИССЛЕДОВАНИЯ}

1. Оценить влияние препарата Умкалор на объективные показатели носового дыхания.

2. Изучить влияние препарата Умкалор на показатели мукоцилиарного клиренса, функциональное состояние слуховой трубы.

3. Изучить антибактериальную активность препарата Умкалор и возможность применения последнего в раннем послеоперационном периоде с целью профилактики септических осложнений.

4. Изучить безопасность применения препарата Умкалор у пациентов после проведения септопластики, эндоназальной максиллотомии и тонзиллэктомии.

\section{МАТЕРИАЛ И МЕТОДЫ ИССЛЕДОВАНИЯ}

На базе ГБУЗ «НИКИО им. Л.И. Свержевского» обследовано 30 пациентов в возрасте от 21 до 53 лет с искривлением перегородки носа (ИПН), вазомоторным ринитом ( $\mathrm{n}=10$ ), кистой верхнечелюстной пазухи ( $=10)$ и хроническим тонзиллитом (ТАФ I, II, $\mathrm{n}=10$ ). Все больные поступали для плановых хирургических вмешательств - септопластики с вазотомией нижних носовых раковин, эндоназальной максиллотомии и тонзиллэктомии под КЭТН. При этом после септопластики перегородку носа шинировали септальными стентами по оригинальной методике А.И. Крюкова и соавт., полость носа тампонировали секционными гидротампонами, которые удаляли через 24 ч после операции [7, 8]. При удалении небных миндалин применяли гольмиевый лазер (Но:YAG) с мощностью излучения 4,8 Вт (энергия - 0,6 Дж, частота - 8,0 Гц) по методике А.И. Крюкова и соавт. [9]. Во время оротрахеальной интубации тампонаду ротоглотки не проводили.

В зависимости от нозологии и вида хирургического вмешательства больные были распределены на 2 группы (рис. 1).

Группа I - 20 больных с ИНП и вазомоторным ринитом и с ИПН + кистой в/ч пазухи.
Группа II - 10 больных с ТАФ I, II.

Пациенты каждой группы были распределены на 2 подгруппы - основную и контрольную (по 10 и 5 человек в каждой с учетом принципа рандомизации). Особенностью симптоматической терапии в основных подгруппах в послеоперационном периоде было применение препарата Умкалор вместо традиционной антибактериальной терапии. Препарат Умкалор назначался перорально. Схема дозирования: по 30 капель 3 р/сут за 30 мин до еды с небольшим количеством жидкости. Первый прием препарата осуществлялся за день до операции, в день операции и в течение 7 дней после операции. С гемостатической целью назначался этамзилат по 2 г внутримышечно в течение 3 дней после операции, ежедневные туалеты носа начиная с 7-го дня после операции: носовой душ 2-3 раза в день в течение 2 недель.

Пациентам контрольных подгрупп проводилась базисная терапия: цефтриаксон и этамзилат по 2 г внутримышечно в течение 3 дней после операции, ежедневные туалеты носа начиная с 7-го дня после операции: носовой душ 2-3 раза в день в течение 2 недель.

Пациентам обеих подгрупп назначалась симптоматическая анальгезирующая терапия.

\section{Критерии включения}

Больные, поступившие в стационар для планового хирургического лечения, - септопластики, конхотомии нижних носовых раковин, максиллотомии (по поводу кистозного процесса), двусторонней тонзиллэктомии (XТ ТАФ І, ІІ степени).

\section{Критерии исключения}

- Одонтогенные синуситы, гнойные синуситы, аллергические риниты.

- Больные с сопутствующей соматической патологией сахарный диабет, заболевания почек и печени.

- Кормление грудью, беременность.

- Чрезмерная чувствительность к компонентам лекарственного средства.

- Имеющаяся у пациента предрасположенность к кровотечениям.

- Одновременное употребление лекарств, ингибирующих коагуляцию.

- Реактивные явления (отек, наличие фибрина и гиперемии) со стороны слизистой оболочки полости носа оценивались при проведении передней риноскопии с последующим эндоскопическим исследованием полости носа на 3, 7 и 16-й день после операции, согласно разработанной шкале от

0-4 баллов. При этом 0 баллов соответствовало отсутствие реактивных явлений:

1 балл - реактивные явления выражены слабо: незначительный отек слизистой оболочки полости носа, незначительное количество фибрина в области нижних носовых раковин; 2 балла - выражены умеренно: умеренный отек слизистой оболочки полости носа, умеренное количество фибрина в области нижних носовых раковин, перегородки носа, незначительное сукровичное отделяемое в носовых ходах; 3 бал- 


\section{Рисунок 1. Дизайн исследования}

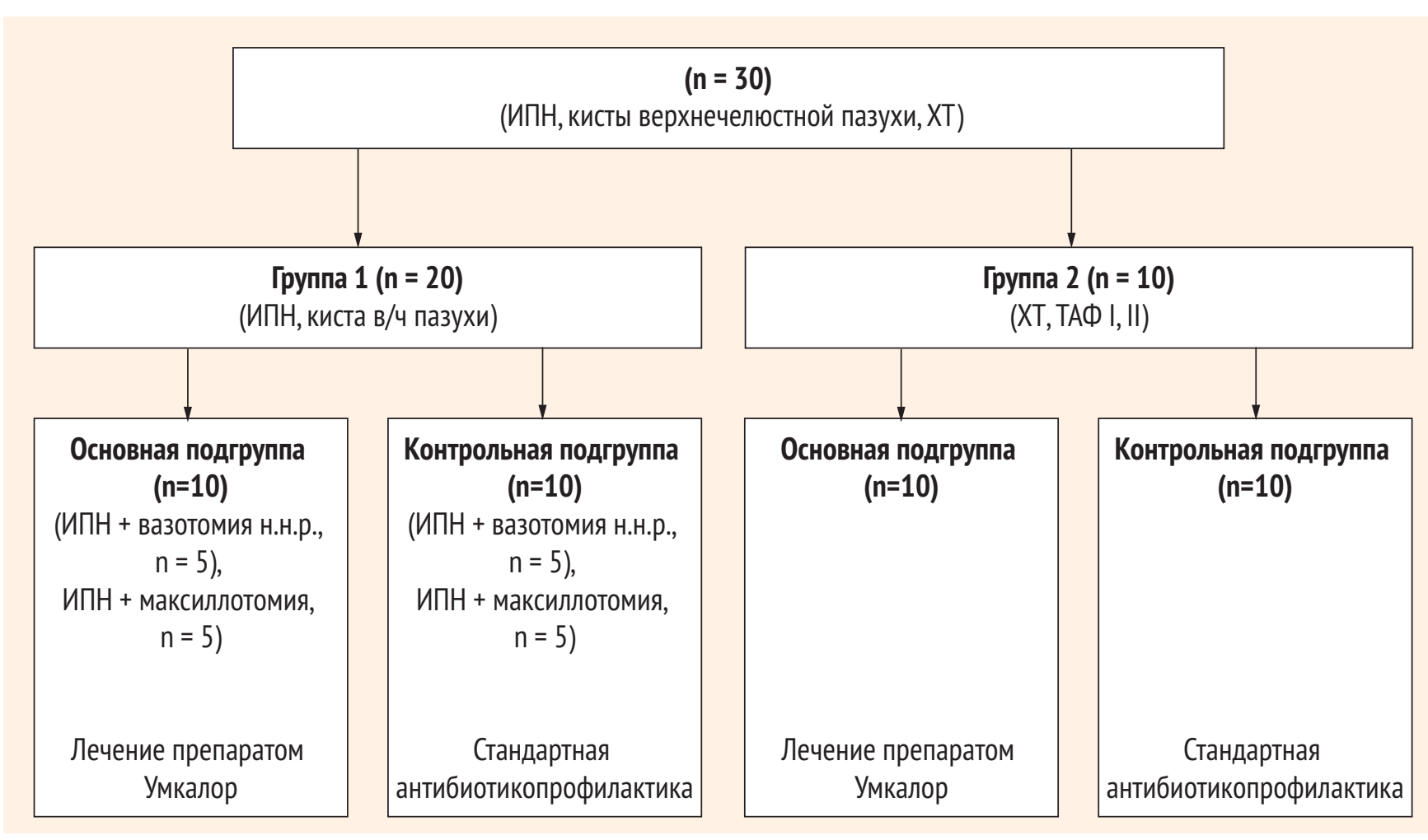

ла - выражены сильно: выраженный отек слизистой оболочки полости носа. Фибрин и сухие корки в области средних и нижних носовых раковин, перегородки носа, умеренное сукровично-геморрагическое отделяемое в носовых ходах; 4 балла - выражены очень сильно: стойкий отек слизистой оболочки полости носа, множественные сухие корки и фибрин в общих носовых ходах, на перегородке носа. Обильное сукровично-геморрагическое отделяемое в носовых ходах.

Оценка обратимой динамики основных клинических симптомов для группы I (затруднения носового дыхания, выделения из носа и тяжести в проекции верхнечелюстHых пазух, повышение температуры тела) и группы II (боль при глотании, озноб, затрудненное глотание) оценивались на основе ежедневного опроса пациентов начиная с 3-х послеоперационных суток по 7-е включительно и во время контрольных осмотров через 16 дней и 21-23 дня после хирургического вмешательства. Анализ полученных результатов проводился с использованием балльной оценки: «0» - отсутствие жалоб и/или симптомов, «1» - незначительно выраженные жалобы и/или симптомы, «2» - умеренно выраженные жалобы и/или симптомы, «3» - выраженные жалобы и/или симптомы, «4»- сильно выраженные жалобы и/или симптомы.

Для объективной оценки восстановления функции носового дыхания на 7-е и 16-е сутки после септопластики и максиллотомии выполнялась ПАРМ (передняя активная риноманометрия). С целью оценки степени дисфункции слуховой трубы (определение показателей интратимпанального давления в -daPa) в разные сроки послеоперационного периода проводилась отомикроскопия, импедансометрия.
Переносимость использования препарата Умкалор оценивали по возникновению нежелательных явлений и по опросу больных основной группы. Пациенты выражали свое мнение об эффективности и переносимости лечения с использованием четырехбалльной системы оценок: «неудовлетворительно», «удовлетворительно», «хорошо» и «отлично». Отдельно регистрировали возможные побочные эффекты, связанные с использованием препарата Умкалор.

\section{РЕЗУЛЬТАТЫ ИССЛЕДОВАНИЯ}

Положительные результаты на фоне применения препарата Умкалор отмечены у всех пациентов основных подгрупп.

Группа I (20 пациентов с патологией носа).

При анализе субъективных клинических симптомов на 3-й день после хиругического лечения у 8 пациентов (80\%) основной подгруппы среди жалоб преобладали выделения из носа, затруднение носового дыхания носило умеренный характер. 9 обследуемых (90\%) контрольной подгруппы беспокоили выраженное затруднение носового дыхания и выделения из носа. Тяжесть в проекции верхнечелюстных пазух у пациентов, перенесших одномоментно с септопластикой и эндоназальную максиллотомию, на 3-е сутки после операции была умеренно выражена у обследуемых обеих подгрупп. Однако уже на 5-й день дискомфорт в проекции пазух отмечали только 3 пациента основной подгруппы и у 4 больных из группы контроля. На 7-е сутки после операции у 8 пациентов основной подгруппы наблюдались выделения из носа и улучшение носового дыхания у 9 пациентов. А через 16 


\section{Рисунок 2. Динамика основных клинических симптомов группы I после операции: а - в контрольной подгруппе;}

\section{б - в основной подгруппе}
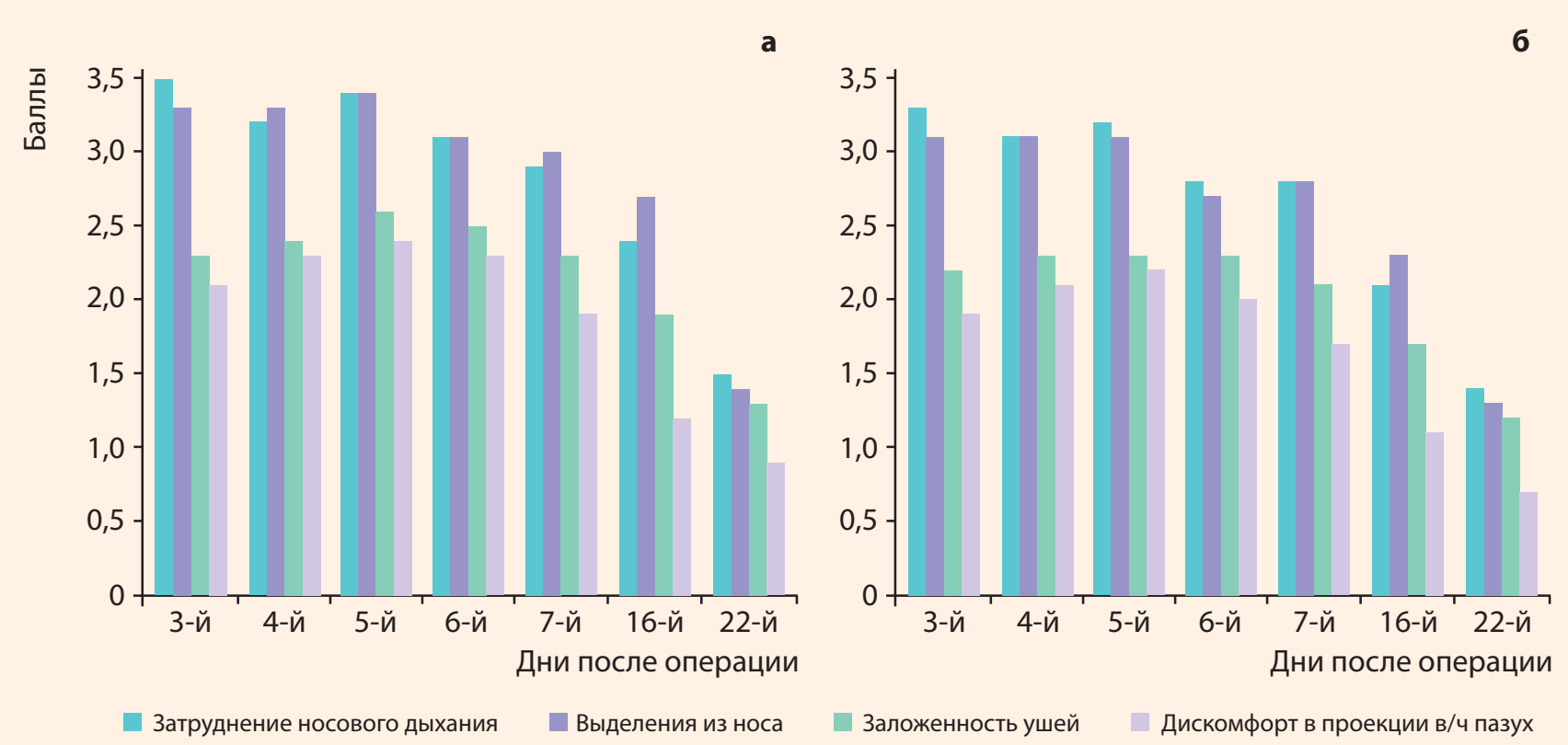

дней после хирургического вмешательства у 9 пациентов отмечалось восстановление носового дыхания и отсутствие дискомфорта в проекции верхнечелюстной пазухи у больных основных подгрупп. У 9 пациентов контрольных подгрупп на 7-е сутки сохранялись сухие корки и сукровичные выделения и умеренное затруднение носового дыхания. Спустя 16 дней после операции у 7 обследуемых основной подгруппы и у 8 контрольной подгруппы продолжали наблюдаться умеренные выделения из носа, легкая степень затруднения носового дыхания. Полное восстановление носового дыхания, купирование выделений из носа в основной и контрольной подгруппах установлены при осмотре через 21-23 дня после операции.

Температура тела у всех больных основной подгруппы нормализовалась к 7-м суткам после операции, тогда как у 2 (20\%) пациентов контрольной подгруппы сохранялась субфебрильная температура к 7-м суткам.

Больных с температурой тела выше $37,5^{\circ} \mathrm{C}$ в послеоперационном периоде ни в основной, ни в контрольной группе не наблюдалось.

Таким образом, основные клинические симптомы, оцениваемые нами по визуально-аналоговой шкале, практически были сопоставимы в основной и контрольной подгруппах группы I.

Динамика клинической симптоматики группы I, по данным ВАШ, отражена на рисунке 2.

Объективная оценка реактивных явлений со стороны слизистой оболочки полости носа сразу после удаления тампонов у пациентов основной подгруппы выявила незначительный отек нижних носовых раковин и скудные сукровичные выделения в общих носовых ходах. У 9 пациентов основной подгруппы улучшение носового дыхания наблюдалось на протяжении 8-10 ч после растампонирования. Затем стали усиливаться реактивные явления со

стороны слизистой оболочки полости носа. На следующий день (3-и сутки после операции) у 8 пациентов при передней риноскопии наблюдались умеренный отек в области нижних носовых раковин, незначительное количество фибрина на нижних носовых раковинах, перегородке носа, скудное сукровичное отделяемое в носовых ходах. В контрольной подгруппе реактивные явления со стороны слизистой оболочки полости носа имели более выраженный характер и нарастали спустя 5-6 ч после удаления тампонов у 9 пациентов (90\%). На 3-й день после хирурги-

Рисунок 3. Динамика реактивных явлений в послеоперационном периоде по данным объективного осмотра (3-й, 7-й, 16-й день)

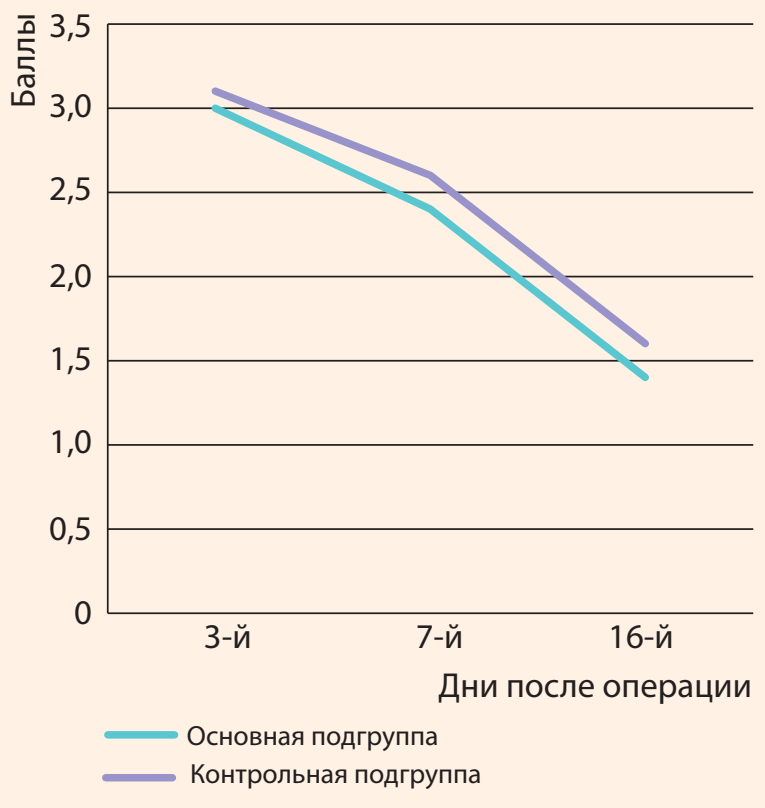




\section{Рисунок 4. Данные передней активной риноманометрии (ПАРМ) в группе I}

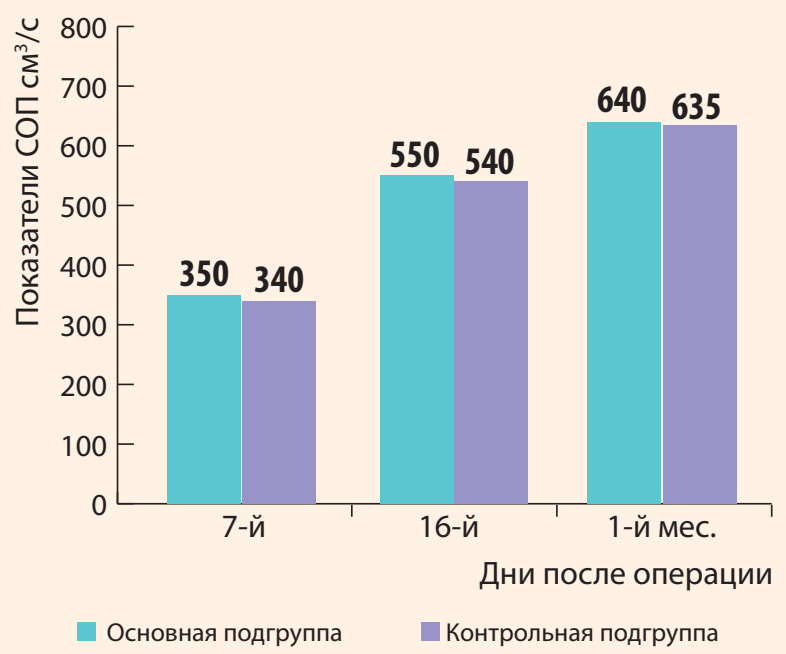

ческого вмешательства у этих больных при эндоскопии отмечалось обильное отделяемое, стойкий отек слизистой оболочки полости носа. Фибрин на нижних носовых раковинах и перегородке носа. На 7-е сутки после операции при эндоскопии полости носа у 9 пациентов основной подгруппы наблюдалось уменьшение отека слизистой оболочки полости носа, небольшое количество фибрина в области задних концов нижних носовых раковин и незначительный отек в области наложенного соустья с верхнечелюстной пазухой. В контрольной подгруппе через 7 дней после операции у 5 (50\%) пациентов присутствовали выраженные реактивные явления в полости носа.

При обследовании пациентов на 16-е сутки после операции в основной подгруппе выявлена практически полная эпитализация слизистой оболочки полости носа и купирование реактивных явлений со стороны слизистой оболочки у 9 пациентов, у 1 пациента присутствовало незначительное количество фибрина в области нижних носовых раковин и умеренный отек.

В группе контроля на 16-й день лечения у 8 обследуемых сохранялись умеренные реактивные явления, отек слизистой оболочки полости носа, обильные сухие корки наблюдались у 2 пациентов, в то время как в основной подгруппе таких пациентов не наблюдалось (рис. 3).

Средний балл в основной подгруппе составил, таким образом, 2,26 \pm 0,12 балла, в контрольной подгруппе $2,43 \pm 0,21$ балла.

Начиная с 7-го дня после операции пациентам первой группы мы проводили объективную оценку носового дыхания с помощью передней активной риноманометрии (ПАРМ).

Из рисунка 4 видно, что показатели СОП (суммарного объема потока воздуха) к месяцу после операции в основной и контрольной подгруппах сопоставимы и составляют соответственно $640 \pm 12$ и $635 \pm 10 \mathrm{~cm}^{3} /$.

По данным литературы, препарат Умкалор обладает секретомоторным эффектом, а именно усиливает цилиар-

\section{УМКАЛОР}

Первый выбор. Быстрое выздоровление
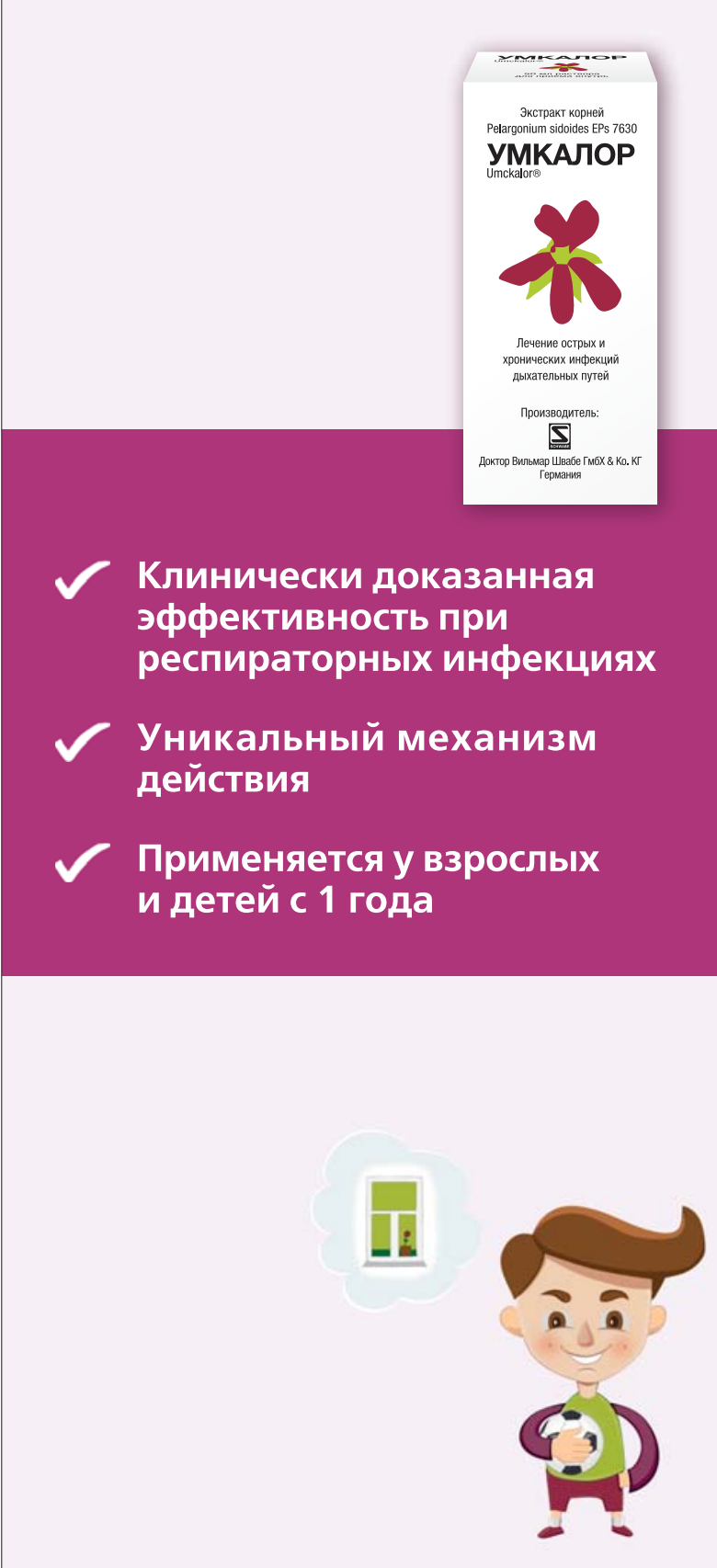

УМКАЛОР

Представительство коммандитного товарищества "Доктор Вильмар Швабе ГмбХ \& Ко. КГ»

119435, Москва, Большой Саввинский пер, д.12, стр.16 Тел.: +7 (495) 665-16-92/93

Факс: +7 (495) 665-16-94

www. schwabe.ru 


\section{Рисунок 5. Средние показатели МЦТ в основной и контрольной подгруппах группы I}

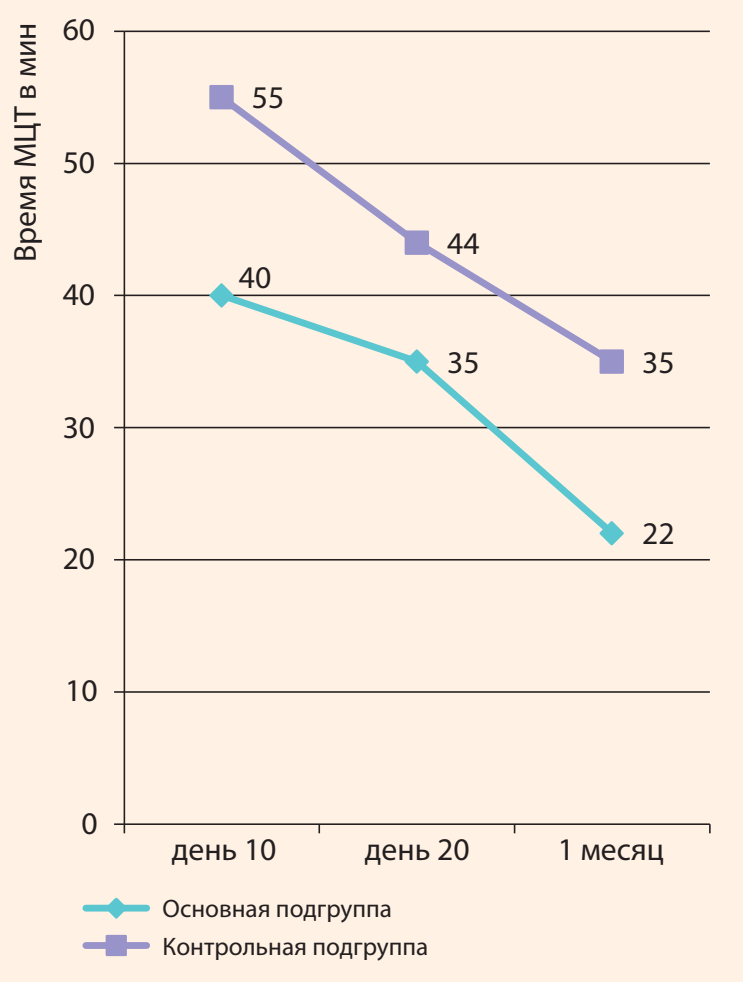

ную активность мерцательного эпителия на 33\% [11]. Исходя из этого, мы изучили влияние препарата Умкалор на показатели МЦТ в послеоперационном периоде.

Как видно из рисунка 5, к 1-му месяцу после операции показатели МЦТ в основной подгруппе составили $22 \pm 3$ мин, в контрольной группе соответственно - $35 \pm 5$ мин.

Величина интратимпанального давления в группе I

Из рисунка 6 видно, что если в основной подгруппе показатели интратимпанального давления нормализуются уже к 7-м суткам, в контрольной подгруппе данные показатели не приближаются к норме даже к 16-му дню после операции. Последний факт свидетельствует о том, что назначение препарата Умкалор в послеоперационном периоде у больных после септопластики, ввиду своей секретолитической и усиливающей цилиарную активность мерцательного эпителия активности, возможно, может быть профилактической мерой в развитии транзиторной дисфункции слуховой трубы, которая в той или иной степени проявляется в послеоперационном периоде после эндоназальных вмешательств.

Группа II (20 пациентов с хроническим тонзиллитом). На вторые сутки после операции выраженные болевые ощущения при глотании были отмечены у 3 пациентов (60\%) основной подгруппы и у 4 пациентов (80\%) контрольной подгруппы. Жалобы на заложенность ушей были у 1 больного (20\%) основной подгруппы и у 2 больных (40\%) контрольной подгруппы (рис. 7).

Температура тела нормализовалась у 4 больных основной подгруппы к 7-м суткам. У одного больного

\section{Рисунок 6. Данные тимпанометрии в группе I}

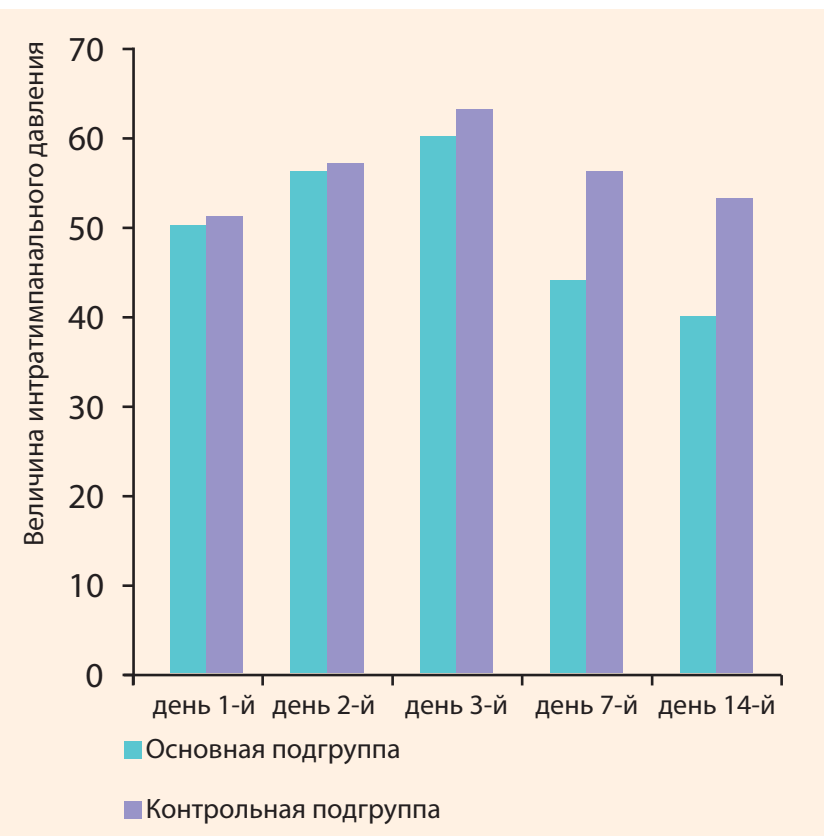

температура тела на 7-е сутки после операции сохранялась до $37,1{ }^{\circ} \mathrm{C}$. На 16 -й день у обследуемых основной подгруппы температура тела не повышалась выше $36,7^{\circ} \mathrm{C}$.

В контрольной подгруппе у 2 пациентов на 7-е сутки температура тела сохранялась в пределах $37,4{ }^{\circ} \mathrm{C}$. На $16-и ̆$ день после операции у одного больного контрольной подгруппы температура тела составила $37,2^{\circ} \mathrm{C}$.

Как видно из рисунка 8, на 8-й день симптомы реактивного воспаления слизистой оболочки ротоглотки на фоне применения препарата Умкалор были сопоставимы у пациентов основной подгруппы по сравнению с контрольной.

Согласно полученным данным, переносимость препарата Умкалор оценивалась пациентами основных подгрупп «удовлетворительно» $(\mathrm{n}=2)$, «хорошо» $(\mathrm{n}=3)$ и «отлично» ( $\mathrm{n}=10)$ (рис. 7).

В заключение следует отметить, что ни один больной из основных подгрупп обеих групп (I, II) по объективным и субъективным показателям не требовал назначения системных антибактериальных препаратов. Каких-либо побочных эффектов, аллергических и других нежелательных реакций у пациентов, принимающих препарат Умкалор, не зафиксировано.

\section{Выводы}

1, При применении препарата Умкалор в качестве антибиотикопрофилактики в раннем послеоперационном периоде в составе комплексной терапии у пациентов после проведения септопластики, эндоназальной максиллотомиии субъективные и объективные показатели репаративного процесса сопоставимы с традиционно проводимой антибиотикопрофилактикой известными антибактериальными препаратами.

2, Препарат Умкалор, благодаря своему секретолитическому эффекту, благоприятно влияет на мукоцилиар- 
Рисунок 7. Динамика субъективных клинических симптомов у больных основной и контрольной подгрупп группы II (средние значения по пятибалльной шкале, $M \pm m, n=5):$ a - в контрольной группе, б - в основной группе
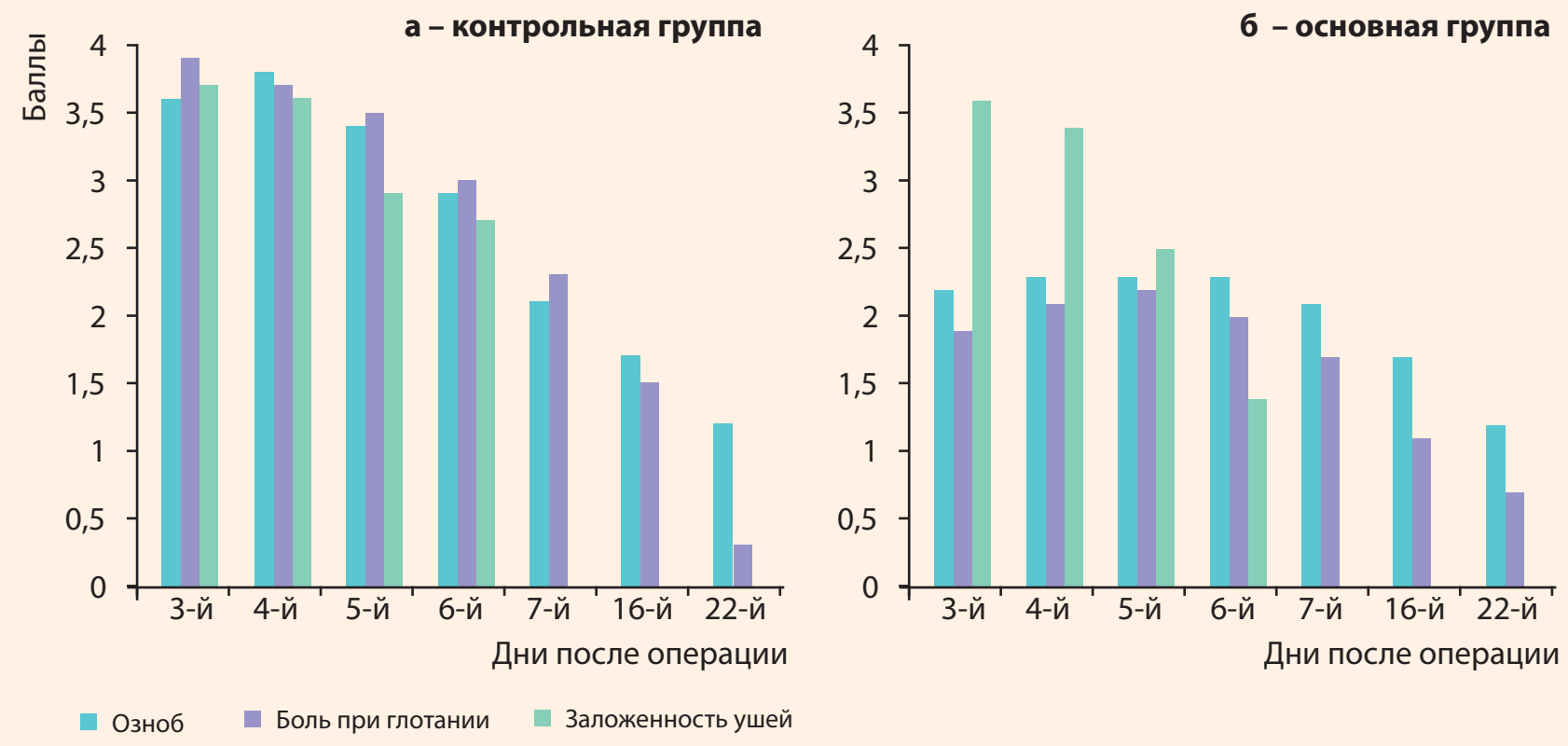

ный транспорт слизистой оболочки полости носа, способствует скорейшей нормализации ее функциональной активности, раннему восстановлению носового дыхания. При применении препарата Умкалор у данной категории больных восстановление дисфункции слуховой трубы происходит в более ранние сроки послеоперационного периода.

3. В связи с быстрой регрессией симптомов при применении препарата Умкалор сокращаются сроки лечения данного контингента больных.

4. В связи с растущей резистентностью к применяемым на сегодняшний день известным антибактериальным препаратам применение относительно нового препарата Умкалор в качестве антибиотикопрофилактики в послеоперационном периоде в составе комплексной терапии у пациентов после «чистых» оториноларингологических вмешательствах является весьма оправданным.

\section{Рисунок 8. Оценка переносимости препарата Умкалор пациентами основных подгрупп}

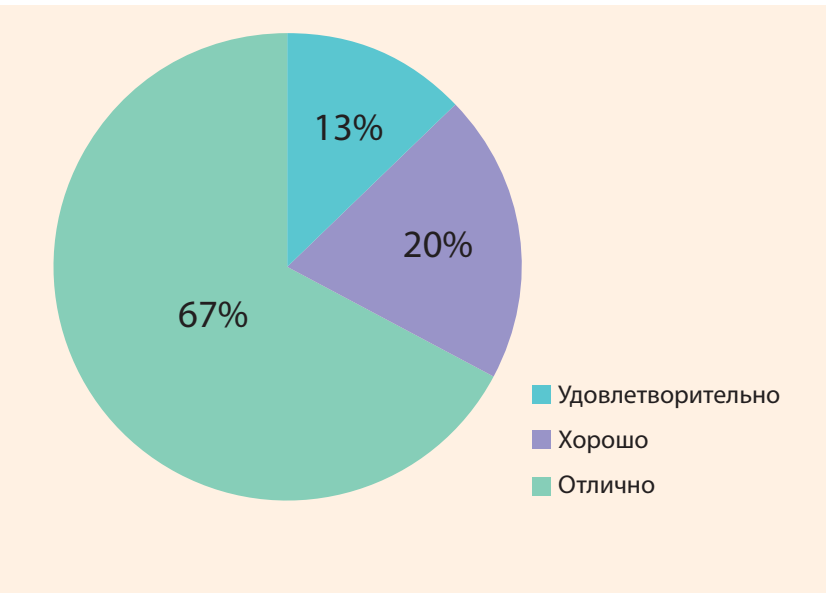

\section{ЛИТЕРАТУРА}

1. Basoli A. Profilassi antibiotica preoperatoria Ediz. Minerva Medica. Torino, 1994.

2. Germiniani R et al. Short-term prophylaxis in elective cholecystectomy. Single-dose ceftriaxone $v$. three doses of cefotaxime: a randomized clinical trial. Clin Trials J, 1988, 25: 131-8.

3. Periti P, Mazzei T. Principles of antimicrobial chemoprophylaxis in surgery. Chemioterapia, 1987; 1: 196-201.

4. Ильенко Л.И., Парфенова А.О., Сырьева Т.Н., Гаращенко Т.И. Опыт применения препарата «Умкалор» при заболеваниях лор-органов у детей. Педиатрическая фармакология, 2007, 5 36-38./Ilienko L.I., Parfenova A.O., Syryeva T.N.,Garaschenko T.I. Experience of application
Umckalor in diseases of ENT-organs in children. Pediatricheskaya Farmakologia, 2007, 5: 36-38.

5. Чучалин А.Г., Берман Б., Лемахер В. Лечение острого бронхита у взрослых экстрактом пеларгонии сидовидной (Pelargonium sidoides) (EPs $\left.{ }^{\circledR} 7630\right)$ : рандомизированное, двойное-слепое, плацебо контролируемое исследование. Пульмонология, 2007, 6: 49-55./ Chuchalin A.G., Berman B., Lemakher V. Treatment of acute bronchitis in adults by extract of Pelargonium sidoides (EPs ${ }^{\circledR}$ 7630): randomized, double blind, placebo-controlled study. Pulmonologia, 2007, 6: 49-55.

6. Bereznoy V, Riley D, Wassmer G, Heger M. Efficacy of extract of Pelargonium sidoides in children with acute non-group Abetahemolytis Streptococcus tonsillopharygits; a randomized, double-blind, placebo-controlled trial. Alternative Therapies, 2003, 9(5): 68-79.

7. Daschner F, Bachert C. Press Conference: Common cold today - chronic sinusitis tomorrow? Forschung und Praxis, Aerzte-Zeitung, 2005, 24/417: 14-15

8. Heger M. Efficacy and safety of an extract of Pelargonium sidoides in the Treatment of the Common Cold. A multicenter, double-blind, placebo-controlled trial. Poster presentation, First International Conference on Natural Products and Molecular Therapy, Cape Town, South Africa, 2005.

9. Matthys $H$, Eisebitt R, Seith B, Heger M. Efficacy and safety of an extract of Pelargonium sidoides (EPs ${ }^{\circledR} 7630$ ) in adults with acute bronchitis. Phytomedicine, 2003, 10(Suppl IV): 7-17. 